\title{
STUDI ANALISIS VARIASI TEMPORAL KANDUNGAN UAP AIR MENGGUNAKAN DATA PENGAMATAN GPS
}

\author{
Fikri Bamahry ${ }^{1}$, Khomsin $^{1}$, Susilo ${ }^{2}$, dan Joni Efendi ${ }^{2}$ \\ ${ }^{1}$ Program Studi Teknik Geomatika FTSP-ITS, Kampus ITS Sukolilo, Surabaya, 60111 \\ ${ }^{2}$ Pusat Jaring Kontrol Geodesi dan Geodinamika BIG, Jl. Raya Jakarta-Bogor Km 46, Bogor \\ Email : khomsin@geodesy.its.ac.id
}

\begin{abstract}
Abstrak
Pengamatan kandungan uap air yang teliti di atmosfer masih menjadi pekerjaan yang belum terselesaikan oleh para peneliti atmosfer. Dikarenakan pergerakan kandungan uap air yang cepat baik temporal maupun spasialnya di atmosfer, pengamatan kandungan uap air yang akurat sangat sulit dilakukan. Global Positioning System atau yang lebih dikenal dengan sebutan GPS telah menawarkan metode baru untuk kandungan uap air yang ada di atmosfer secara akurat. Dengan memanfaatan hitungan estimasi perlambatan dan pembelokan sinyal GPS di lapisan troposfer serta dilengkapi dengan data pengukuran meteorologi permukaan, kita dapat mengetahui berapa kandungan uap air yang ada di atmosfer dengan akurat. Pada penelitian ini digunakan 8 (delapan) stasiun GPS CORS Badan Informasi Geospasial (BIG) untuk mengestimasi kandungan uap air di sekitar wilayah lokasi penelitian, diantara lain: Tuban, Lamongan, Mojokerto, Surabaya, Nganjuk, Malang, Pasuruan, dan Sampang. Zenith Tropospheric Delay (ZTD) yang diestimasi dari pengamatan GPS ini diekstraksi menjadi kandungan uap air menggunkan data meteorologi permukaan. Data kandungan uap air yang didapatkan dari pengamatan GPS di Surabaya memiliki korelasi yang baik dengan hasil pengamatan meteorologi konvensial, yaitu balon radiosonde. Dengan nilai bias 0,761 mm dan korelasi 98,3\%, perbandingan data tersebut dapat dikatakan baik. Dari hasil plotting grafik variasi temporal, didapatkan informasi bahwa rerata kandungan uap air bulanan pada musim kemarau (Mei - Oktober 2012) berada antara 20 - 45 $\mathrm{mm}$, sedangkan pada musim hujan (November-April 2012) berada antara $45-65 \mathrm{~mm}$. Baik dari grafik variasi temporal kandungan uap air dan hasil penggambaran variasi spasial didapatkan informasi bahwa bulan terkering pada tahun 2012 adalah bulan Agustus, dan bulan terbasah pada tahun 2012 adalah bulan Januari. Hal ini dimungkinkan karena pengaruh siklus Monsoon Asia-Australia yang mempengaruhi cuaca dan iklim di Indonesia.
\end{abstract}

Kata Kunci: Uap Air, GPS, ZTD, Radiosonde, Monsoon Asia-Australia

\section{PENDAHULUAN}

Uap air merupakan zat yang memiliki peran penting dalam dinamika proses di atmosfer. Peran yang dimilikinya tidak hanya terbatas pada proses penyerapan dan penyinaran energi dari matahari, tetapi juga merupakan sebagai salah satu unsur pembuat awan, aerosol, dan zat kimia yang berada lapisan atmosfer yang rendah. Oleh karena itu, pengamatan zat ini menjadi penting karena perubahan yang terjadi pada zat ini baik secara temporal maupun spasial akan berpengaruh terhadap perubahan cuaca/iklim dalam skala global dan regional (Liu, 2001).

Global Positioning System (GPS) merupakan suatu sistem yang memanfaatkan sinyal radio untuk keperluan navigasi dan penentuan posisi (Seeber, 2003). Sinyal yang ditransimisikan dari satelit GPS mengalami perlambatan waktu ketika melewati lapisan atmosfer. Perlambatan tersebut merupakan akibat dari perubahan secara spasial dan temporal dari atmosfer (Karabatic, 2011). Oleh karena itu, akhir-akhir ini dilakukan penelitian atmosfer dengan memanfaatkan perlambatan sinyal GPS sebagai parameter untuk menentukan variasi spasial dan temporal dari atmosfer. Metode ini disebut inversi GPS (Bevis, 1992).

Didasarkan pada perambatan sinyal GPS, lapisan atmosfer dibagi menjadi 2 (dua) macam lapisan, yaitu lapisan ionosfer dan troposfer. Lapisan ionosfer merupakan medium dispersive, yang berarti bahwa delay ini bergantung dari frekuensi sinyal GPS. Delay yang disebabkan oleh lapisan ini dapat direduksi atau dieleminir menggunakan teknik kombinasi linier frekuensi sinyal GPS. Berbeda halnya dengan lapisan troposfer, lapisan ini merupakan lapisan atmosfer yang bersifat nondispersive yang berarti tidak bergantung pada frekuensi sinyal GPS (Wells, 1999). 
Seperti yang dijelaskan sebelumnya, bahwa uap air tersebar di lapisan atmosfer yang rendah (troposfer), oleh karena itu pada penelitian ini dilakukan pengestimasian total delay troposphere yang selanjutnya digunakan untuk sebagai parameter untuk mengestimasi variasi temporal kandungan uap air di lokasi penelitian.

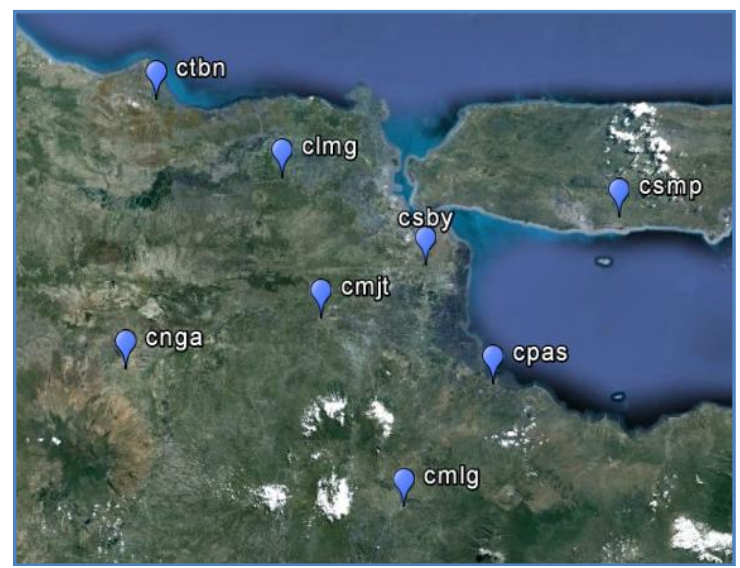

Gambar 1. Lokasi persebaran stasiun GPS CORS BIG yang digunakan pada peneleitian ini

\section{METODOLOGI PENELITIAN}

A. Data dan Lokasi Penelitian

Data observasi yang digunakan adalah data yang berasal dari 8 (delapan) stasiun tetap GPS kontinyu Badan Informasi Geospasial (BIG). Stasiun GPS yang digunakan antara lain: ctbn (Tuban), clmg (Lamongan), csby (Surabaya), cmjt (Mojokerto), cnga (Nganjuk), cmlg (Malang), cpas (Pasuruan), csmp (Sampang). Dilengkapi dengan data meteorologi permukaan yang berasal dari sensor meteorologi dari lokasi penelitian, dilakukan estimasi terhadap kandungan uap air di kawasan lokasi penelitian.

Pada penelitian ini, diikutsertakan data dari 2 (dua) stasiun International GNNS Service (IGS) yaitu bako, dan darw. Stasiun IGS darw diikutsertakan karena untuk mengetahui nilai absolut dari ZTD dibutuhkan jarak lebih dari 1000 km antar stasiun GPS (Susilo, 2012).

\section{B. Tahap Pemrosesan Data GPS}

Dalam pemrosesan data digunakan software pengolahan GAMIT 10.4 untuk menghitung solusi harian dari pengamatan GPS, yang selanjutnya digunakan sebagai parameter untuk mengestimasi kandungan uap air. Pada penelitian ini, fungsi pemetaan yang digunakan adalah fungsi pemetaan (Neill, 1996). Dan koordinat yang digunakan dalam pengolahan beracuan pada ITRF 2008 (International Terrestrial Reference Frame 2008).

\section{Tahap Validasi dan Uji Perbandingan}

Untuk menguji nilai kebenaran dari total delay troposfer, maka delay troposfer yang telah dikonversi menjadi Zenith Delay Troposphere (ZTD) dibandingkan dan diuji korelasinya dengan Zenith Path Delay (ZPD) yang merupakan ZTD versi International GNSS Service (IGS).

Setelah proses validasi diatas, data kandungan uap air (PWV) yang diekstraksi dari delay troposfer dibandingkan dengan hasil pengamatan kandungan uap air konvensional yaitu balon radiosonde. Hal ini dilakukan untuk mengukur tingkat kedekatan hubungan hasil PWV GPS dengan PWV dari balon radiosonde.

\section{Tahap Penggambaran}

Untuk menganalisa variasi temporal dilakukan penggambaran secara temporal. Penggambaran ini dilakukan dengan merata-ratakan PWV pada jam yang sama di hari yang berbeda dalam satu bulan yang sama lalu digambarkan dalam grafik dengan sumbu-X adalah jam, dan sumbu-Y adalah PWV. Hal ini berguna untuk menentukan bulan terkering dan bulan terbasah dari masing-masing titik lokasi penelitian ataupun lokasi penelitian secara umum.

\section{HASIL DAN PEMBAHASAN}

A. Validasi ZTD GPS oleh ZPD IGS

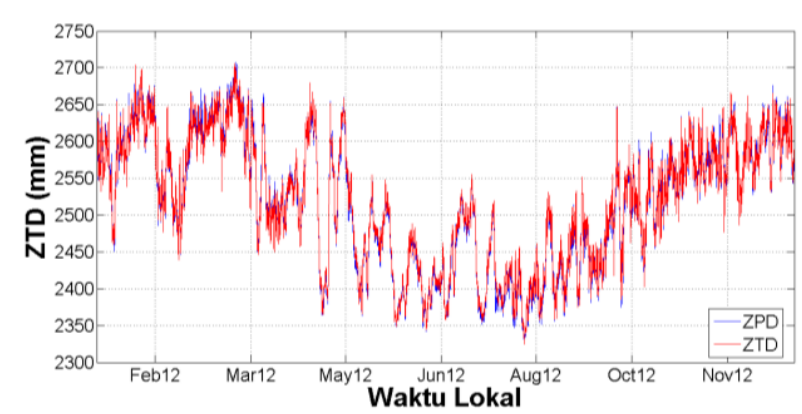




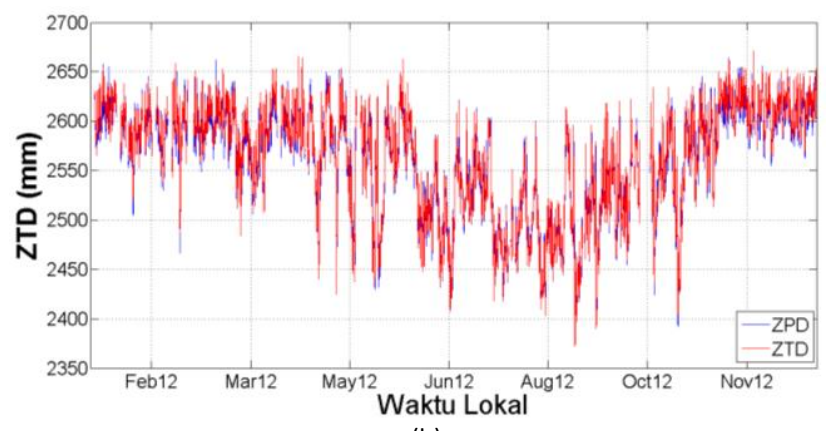

(b)

Gambar. 2. Grafik perbandingan nilai ZTD GPS dengan nilai ZPD IGS. (a) di stasiun Darw, dan (b) di stasiun Bako

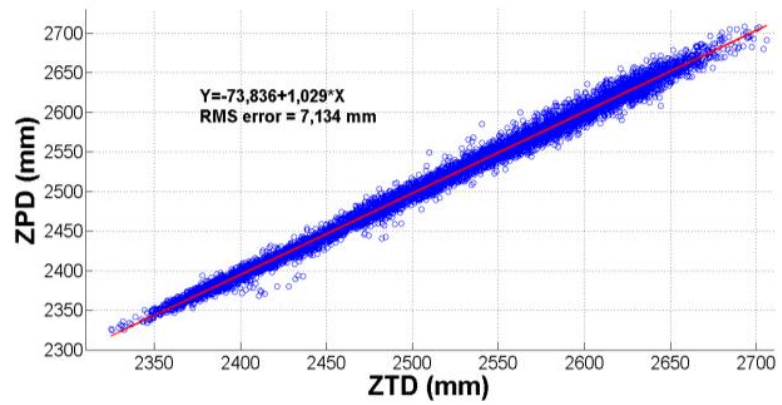

(a)

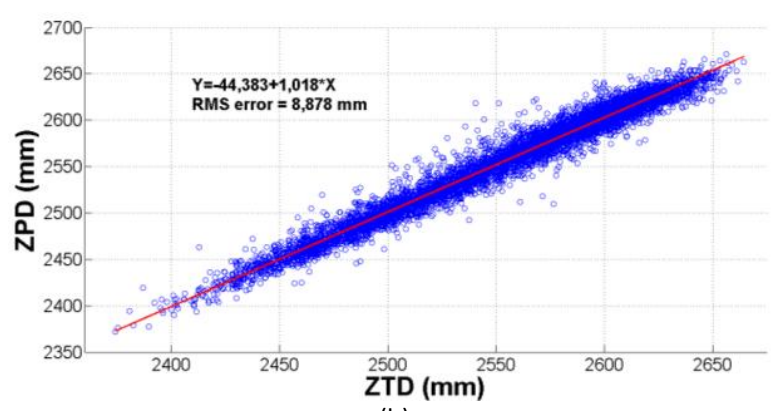

(b)

Gambar. 3. Scatter Plot ZTD GPS dan ZPD IGS. (a) di stasiun Darw, dan (b) di stasiun Bako

Seperti yang dijelaskan pada uraian peneletian, bahwa validasi ini bertujuan untuk mengetahui tingkat kebenaran ZTD yang diperoleh dari data pengolahan data pengamatan GPS. Validasi dilakukan dengan di 2 (dua) stasiun IGS yaitu darw dan bako.

Dari gambar diatas dapat dilihat kemiripan hasil plotting antara ZTD hasil pengolahan data pengamatan GPS baik di stasiun bako mapupun darw dengan data ZPD dari IGS. Untuk dapat melihat kemiripannya, maka digambarkan grafik scatter plot (Gambar 3). Hal ini bertujuan untuk mengetahui besar korelasi antara ZTD dan ZPD. Regresi yang digunakan adalah Robust Regression. 96
Dari hasil perhitungan menggunakan robust regression pada stasiun Darw didapatkan nilai korelasi 99,6\% dengan RMS error 7,134 mm.

Dan pada stasiun Bako didapatkan nilai korelasi 98,5\% dengan RMS error 8,611 mm. Dari tabel 1 diatas dapat dilihat bahwa nilai rerata dari bias antara ZTD dan ZPD adalah 2,080 $\mathrm{mm}$, dengan rerata std (standar deviasi) sebesar $6,841 \mathrm{~mm}$, dan korelasi sebesar 0,991. Dengan nilai-nilai tersebut, maka dapat disimpulkan bahwa ZTD yang dihasilkan dari penelitian ini memiliki kesesuaian yang sangat tinggi dengan nilai ZPD dari IGS. Selisih antara ZTD yang dihasilkan dari pengolahan data GPS dengan nilai ZPD dari IGS dimungkinan terjadi karena adanya perbedaan dalam metode pengolahan data GPS.

\begin{tabular}{|c|c|c|c|c|}
\hline Stasiun & & bako & darw & rerata \\
\hline & bias (mm) & 2,292 & 1,868 & 2,080 \\
\hline \multirow[t]{3}{*}{ Selisih } & std $(\mathrm{mm})$ & 9,716 & 3,966 & 6,841 \\
\hline & data & 8.121 & 8.160 & \\
\hline & intersep & $-44,383$ & $-73,836$ & $-59,110$ \\
\hline \multirow[t]{3}{*}{ Regresi } & koef regresi & 1,018 & 1,029 & 1,024 \\
\hline & rmse (mm) & 8,878 & 7,134 & 8,006 \\
\hline & korelasi & 0,985 & 0,996 & 0,991 \\
\hline
\end{tabular}

\section{B. Perbandingan Data PWV dari GPS dan Radiosonde}

Uji perbandingan ini dilakukan untuk melihat kekuatan hubungan PWV hasil pengolahan data GPS dengan teknik pengukuran PWV secara konvensional, yaitu balon radiosonde. Dalam penelitian ini diambil contoh uji perbandingan PWV GPS di stasiun CSBY dan peluncuran balon udara di kota Surabaya yang diupload oleh Wyoming. 


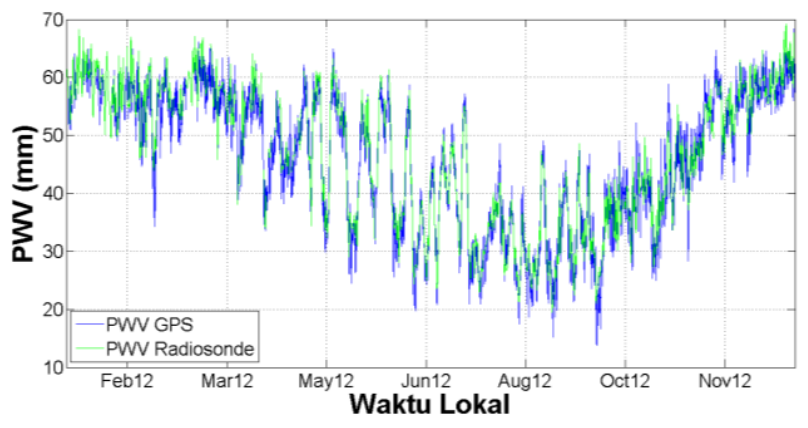

Gambar. 4. Grafik Perbandingan nilai PWV dari GPS dan PWV dari balon radiosonde

Dari gambar diatas dapat dilihat kemiripan hasil plotting antara PWV hasil pengolahan data pengamatan GPS dengan data PWV dari balon radisonde. Untuk dapat melihat kekuatan hubungan dari 2 data ini, maka digambarkan grafik scatter plot.

Dari hasil perhitungan nilai bias yang didapatkan antara PWV GPS dan PWV Radiosonde adalah $0,761 \mathrm{~mm}$, dengan nilai std (standar deviasi) sebesar 2,203 mm, korelasi sebesar 98,3\%, dan RMS error 2,14 mm. Dengan nilai-nilai tersebut, maka dapat disimpulkan bahwa PWV GPS memiliki kesesuaian yang tinggi dengan PWV Radiosonde, Namun pada penelitian ini belum ada koreksi tinggi antara pengamatan menggunakan GPS dan pengamatan menggunakan Radiosonde.

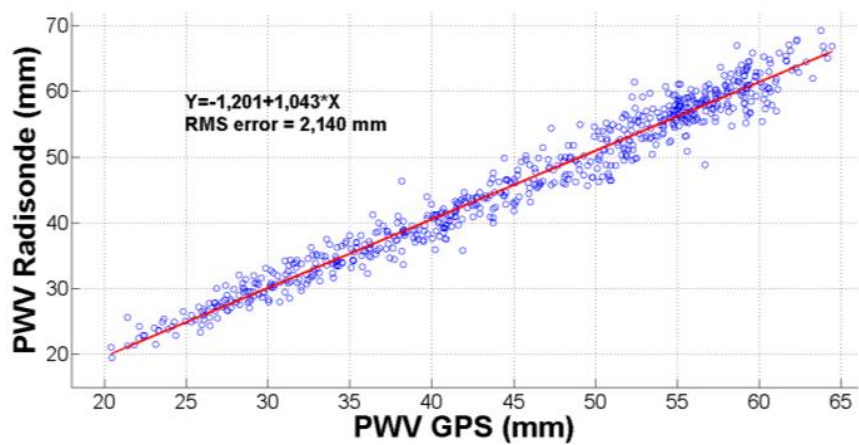

Gambar. 5. Scatter Plot PWV dari GPS dan PWV dari balon radiosonde

\section{Analisa Bulan Terkering dan Bulan Terbasah}

Analisa ini dilakukan dengan menggambarkan PWV pada jam yang sama, hari yang beda dalam satu bulan. Penggambaran ini selanjutnya dilakukan dalam grafik temporal untuk melihat grafik bulan yang tertinggi dan grafik bulan yang terendah. Grafik bulan tertinggi menandakan bahwa kandungan uap airnya banyak sehingga dapat dikatakan bulan terbasah. Sebaliknya, grafik bulan terendah menandakan bahwa kandungan uap air sedikit sehingga dapat dikatakan bulan terkering.

Pada penelitian ini akan dilakukan analisa bulan terkering dan bulan terbasah di masing-masing lokasi penelitian, dan pada lokasi penelitian secara umum.
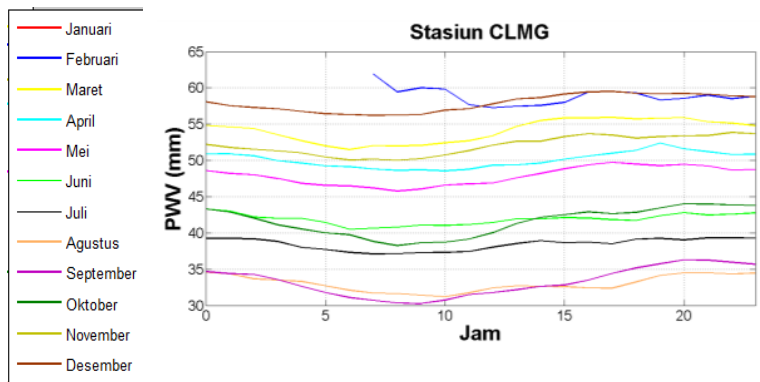

Gambar. 6. Grafik temporal PWV di stasiun CLMG (Lamongan)

Dari gambar 6 dapat disimpulkan bahwa pada stasiun CLMG bulan terkering adalah bulan agustus, hal ini dikarenakan grafik temporal dari bulan agustus berkisar dari $31,197 \mathrm{~mm}$ sampai $34,599 \mathrm{~mm}$. Dan bulan terbasah adalah bulan desember, hal ini dikarenakan grafiknya yang berkisar dari 56,229 mm sampai 59,519 mm.
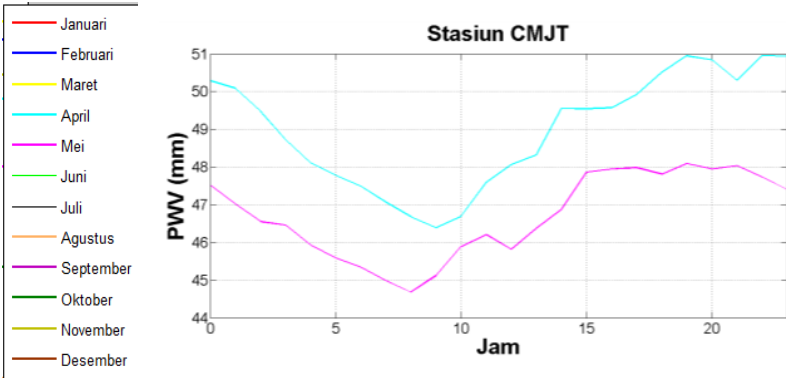

Gambar. 7. Grafik temporal PWV di stasiun CMJT (Mojokerto)

Dari gambar 7 masih belum dapat disimpulkan mengenai bulan terbasah dan bulan terkering pada stasiun CMJT, hal ini dikarenakan ketersediaan data dari stasiun pengamat. Namun, dari grafik temporal diatas didapatkan informasi bahwa pada bulan april kisaran PWV berada dari 46,389 $\mathrm{mm}$ sampai 50,949 $\mathrm{mm}$. Dan informasi bahwa pada bulai mei PWV di stasiun pengamat berkisar dari 44,679 $\mathrm{mm}$ sampai 48,03 $\mathrm{mm}$. 


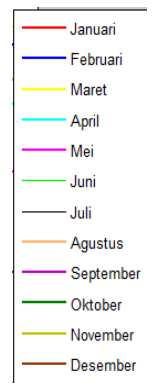

Gambar. 8. Grafik temporal PWV di stasiun CMLG (Malang)

Dari gambar 8 diatas dapat disimpulkan bahwa bulan terkering pada stasiun CMLG adalah bulan agustus, hal ini dikarenakan grafik temporal dari bulan agustus berkisar dari 23,684 $\mathrm{mm}$ sampai 30,687 mm. Dan bulan terbasah adalah bulan januari, hal ini dikarenakan grafik temporalnya yang berkisar dari 48,606 $\mathrm{mm}$ sampai $52,926 \mathrm{~mm}$.
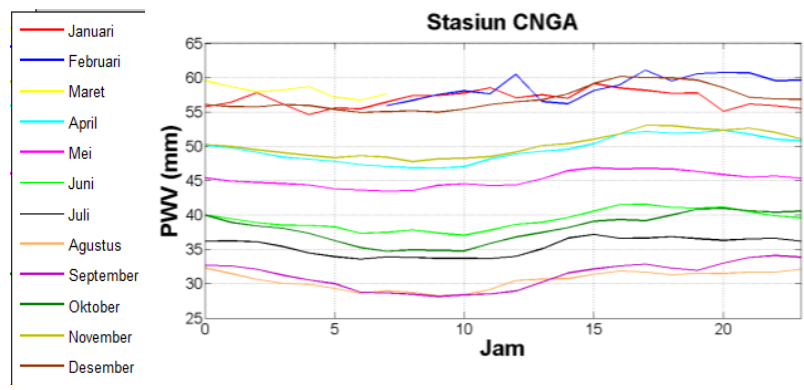

Gambar. 9. Grafik temporal PWV di stasiun CNGA (Nganjuk)

Dari gambar 9 diatas dapat disimpulkan bahwa bulan terkering pada stasiun CNGA adalah bulan agustus, hal ini dikarenakan grafik temporal dari bulan agustus berkisar dari 28,261 mm sampai $32,3 \mathrm{~mm}$. Dan bulan terbasah adalah bulan desember, hal ini dikarenakan grafiknya yang berkisar dari 54,929 mm sampai 60,145 mm.
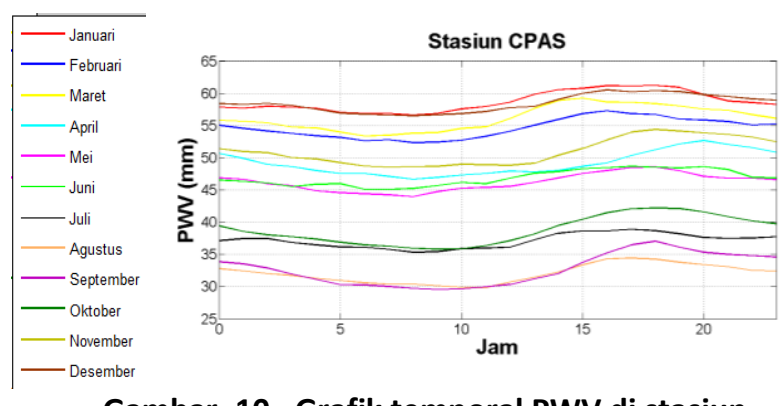

Gambar. 10. Grafik temporal PWV di stasiun CPAS (Pasuruan)
Dari gambar 10 disamping dapat disimpulkan bahwa bulan terkering pada stasiun CPAS adalah bulan agustus, hal ini dikarenakan grafik temporal dari bulan agustus berkisar dari 29,86 mm sampai 34,445 mm. Dan bulan terbasah adalah bulan januari, hal ini dikarenakan grafiknya yang berkisar dari 56,625 mm sampai 61,224 mm.
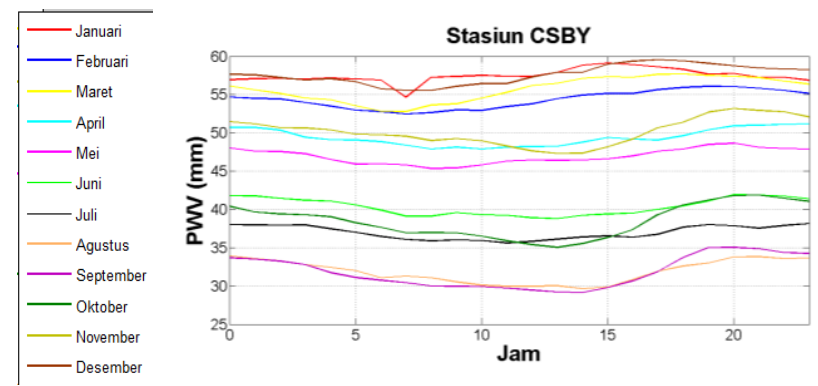

Gambar. 11. Grafik temporal PWV di stasiun CSBY (Surabaya)

Dari gambar 11 diatas dapat disimpulkan bahwa bulan terkering pada stasiun CSBY adalah bulan september, hal ini dikarenakan grafik temporal dari bulan september berkisar dari 29,126 mm sampai 35,03 mm. Dan bulan terbasah adalah bulan desember, hal ini dikarenakan grafiknya yang berkisar dari 55,542 $\mathrm{mm}$ sampai 59,539 mm.
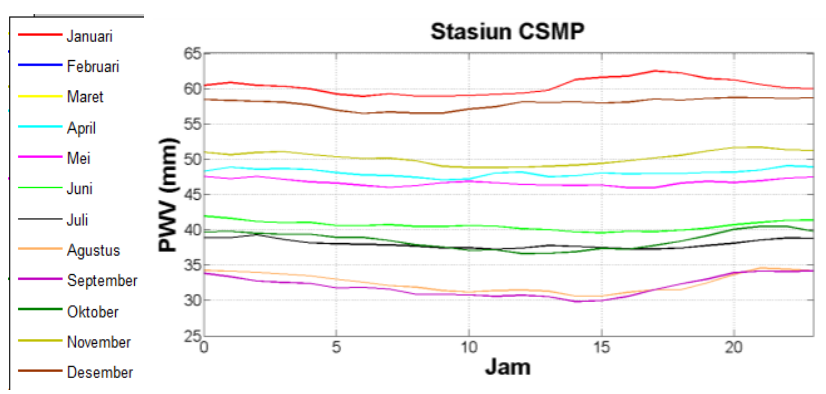

Gambar. 12. Grafik temporal PWV di stasiun CSMP (Sampang)

Dari gambar 12 dapat disimpulkan bahwa untuk stasiun CSMP bulan terkering adalah bulan september, hal ini dikarenakan grafik temporal dari bulan september berkisar dari 29,829 mm sampai 34,162 mm. Dan Dan bulan terbasah adalah bulan januari, hal ini dikarenakan grafiknya yang berkisar dari $58,888 \mathrm{~mm}$ sampai $62.48 \mathrm{~mm}$.

Dari gambar 13 disamping disimpulkan bahwa bulan terkering pada stasiun CTBN adalah bulan agustus, hal ini dikarenakan grafik temporal dari bulan agustus berkisar dari $31,838 \mathrm{~mm}$ sampai 35,859 $\mathrm{mm}$. Dan bulan terbasah adalah bulan 
desember, hal ini dikarenakan grafiknya yang berkisar dari 58,153 $\mathrm{mm}$ sampai 61,142 $\mathrm{mm}$.
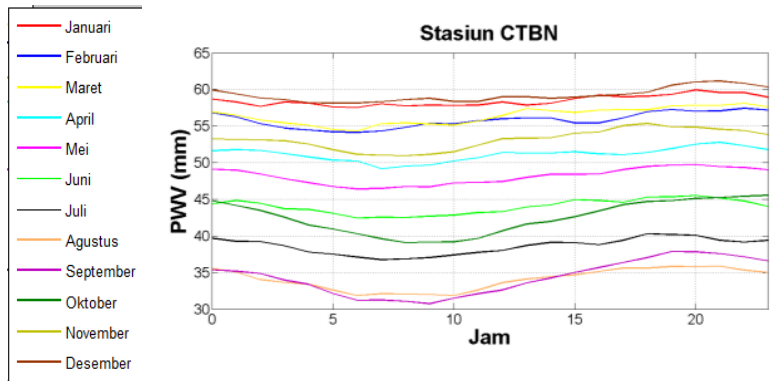

Gambar. 13. Grafik temporal PWV di stasiun CTBN (Tuban)

Dari masing-masing penjelasan grafik tersebut dapat disimpulkan bahwa bulan terbasah dan bulan terkering dari masing-masing lokasi stasiun pengamat dapat dituliskan kembali pada tabel berikut ini.

Tabel 2. Bulan Terbasah dan Bulan Terkering

\begin{tabular}{lcc}
\hline \hline Station & Bulan Terkering & Bulan Terbasah \\
\hline CLMG & Agustus & Desember \\
CMJT & - & - \\
CMLG & Agustus & Januari \\
CNGA & Agustus & Desember \\
CPAS & Agustus & Januari \\
CSBY & September & Desember \\
CSMP & September & Januari \\
CTBN & Agustus & Desember \\
\hline \hline
\end{tabular}

Untuk mendapatkan menyimpulkan bulan terbasah dan bulan terkering secara umum lokasi penelitian, nilai PWV yang telah dirata-rata pada jam yang sama, pada hari berbeda di bulan yang sama diratakan dengan nilai PWV di semua stasiun dan di gambarkan grafik temporalnya.
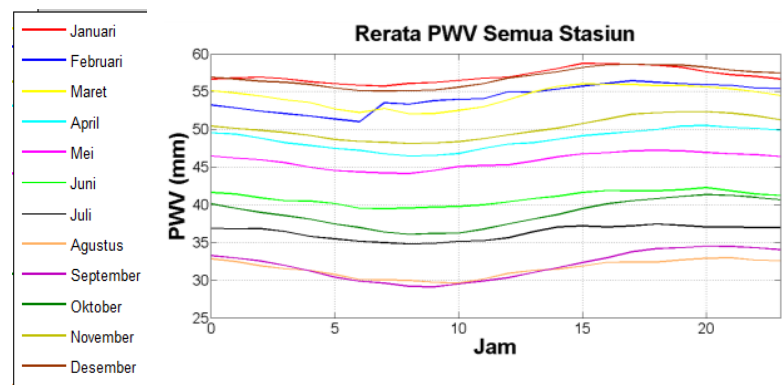

Gambar. 14. Grafik rerata temporal PWV Semua Stasiun

Dari grafik diatas dapat disimpulkan bahwa secara umum di lokasi penelitian bulan terkering adalah bulan agustus, hal ini dikarenakan grafiknya yang berkisar dari 29,597 $\mathrm{mm}$ sampai 32,948 $\mathrm{mm}$. Sedangkan bulan terbasah adalah bulan januari, hal ini dikarenakan grafiknya berkisar dari 55,708 $\mathrm{mm}$ sampai $58,717 \mathrm{~mm}$.

\section{KESIMPULAN dan SARAN}

Dari penelitian ini dapat disimpulkan beberapa informasi yang penting, yaitu antara lain:

1. Variasi temporal kandungan uap air di Lamongan, Mojokerto, Malang, Nganjuk, Pasuruan, Surabaya, Sampang, dan Tuban pada tahun 2012 berkisar antara $\pm 20-65$ $\mathrm{mm}$.

2. Pada musim penghujan (Nopember - April 2012) kandungan uap air berkisar antara \pm 45

- 65 mm. Sedangkan pada musim kemarau (Mei - Oktober 2012) kandungan uap air berkisar antara $\pm 20-45 \mathrm{~mm}$.

3. Secara umum pada tahun 2012 bulan terbasah di lokasi penelitian adalah bulan Januari, sedangkan bulan terkering adalah bulan Agustus.

4. Variasi temporal pada lokasi penelitian ini masih sesuai dengan fenomena siklus Monsoon Asia-Australia.

Secara umum, data GPS dapat dijadikan informasi mengenai temporal kandungan uap air yang mempengaruhi siklus cuaca/iklim. Oleh karena itu diperlukan penelitian lanjutan baik dalam pengembangan metode GPS sebagai pemantau kandungan uap air, ataupun metode-metode yang dapat digunakan untuk kepentingan analisa meteorologi. 


\section{UCAPAN TERIMA KASIH}

Penulis F.B. mengucapkan terima kasih kepada Pusat Jaring Kontrol Geodesi dan Geodinamika, Badan Informasi Geospasial, Indonesia yang telah memberikan dukungan berupa data dan sarana prasarana yang sangat berguna dalam menunjang penelitian ini.

\section{DAFTAR PUSTAKA}

Liu, Y., Y. Chen, HB Iz, Precision of Precipitable Water Vapor from Radiosonde Data for GPS Solution. Geomatica 54(2) (2000): 171-175.

Seeber, G, Satellite Geodesy: Foundation, Methods, and Application. Berlin (2003): Walter de Gruyter.

Karabatic, A., "Precise Point Positioning (PPP) - An Alternative Technique for Ground Based GNSS Troposphere Monitoring", Dissertation,
Vienna University of Technology, Faculty of Mathematics and Geoinformation (2011).

Bevis, M., S. Businger, T. Herring, C. Rocken, R. Anthes, and R. Ware, GPS Meteorology: Remote Sensing of Atmospheric Water Vapor using the Global Positioning System. J. Geophys. Res., 97, 15,787-15,801,(1992).

Wells, D., Beck, N., Delikaraoglou, D., Kleusberg, A., Krakiwsky, E.J., Lachapelle, G., Langley, R.B., Nakiboglu, M., Schwarz, K.P, Tranquilla, J.M., Vanicek, P. Guide to GPS Positioning. Canada (1999): University of New Brunswick.

Susilo, Pemantauan Precipitable Water Vapor (PWV) di Wilayah Jawa Barat menggunakan GPS Kontinu. Thesis, Institut Teknologi Bandung. (2012)

Neill, A.E., Global Mapping Functions for The Atmospheric Delay at Radiowavelenghts, J. Geophys. Res. (1996), 101,3227-3246. 